\title{
Outbreak of Peritonitis in a Continuous Ambulatory Peritoneal Dialysis Population Following the Use of Contaminated Peritoneal Dialysis Fluids
}

\author{
Sarra Elamin*, Maysoon Al-Amin, Ahmed Hashim, Ahmed Amin, Shaza Nasereldeen, Rabab Tagelsir,
} Suhair Abdul-Sattar, Hasan Abuaisha

Sudan Peritoneal Dialysis Program

\begin{abstract}
Introduction: Most cases of peritonitis during continuous ambulatory peritoneal dialysis (CAPD) are attributed to breaches of the aseptic technique. In this report, we describe an outbreak of CAPD related peritonitis that followed the use of potentially contaminated PD fluid.
\end{abstract}

Outbreak report: CAPD was introduced in the adult nephrology unit at Soba University Hospital in December 2008 with fairly satisfactory functioning and results. In June 2009, we obtained a new supply of PD fluids and started using it. Soon afterwards, a mould was found inside a new unused dialysate bag. During the following days, six patients were diagnosed to have PD related peritonitis. All patients in the unit were immediately shifted to another brand of PD fluids. Enquiry revealed that this supply of PD fluid was stored in a warm and humid environment. We surveyed the 1469 bags in the hospital stock and found another three bags $(0.2 \%)$ that contained visible mould by the naked eye. The four contaminated bags contained $2.5 \%$ dextrose and were from different batches. All of them had lost the negative vacuum between the inner bag and the outer plastic envelope, but had no obvious tears in the envelope and no obvious fluid leakage. Our peritonitis rate before the outbreak was one episode in 21.7 patient-months. This sharply rose to one episode in 2.5 patient-months during the month of the outbreak, and dropped down to one episode in 17.8 patient-months in the 6-months following the outbreak.

Conclusion: Contamination of PD fluids can occur during handling and storage. Patients should meticulously examine each bag before usage. Any bag that has lost the vacuum between the inner bag and its outer envelope is potentially breached and should not be used.

* Corresponding author; PO Box 363, Khartoum, Sudan

E mail: sarraelamin@sudanpd.org
Keywords: Contamination; Fungal peritonitis; Outbreak; Penicillium spp.; Peritoneal dialysis

\section{The authors declared no conflict of interest}

\section{Introduction}

Continuous ambulatory peritoneal dialysis (CAPD) was introduced as a treatment modality for end stage renal disease (ESRD) patients in 1976. Successive improvements in the technique resulted in the current universal use of disposable plastic twin-bag disconnectsystems by all patients undergoing this treatment modality.

These improvements in the technique have resulted in marked reduction of PD-related infections. Most peritonitis episodes are attributed to breaches of the aseptic technique during the exchange procedure or migration of bacteria from the skin to the peritoneal cavity through the subcutaneous tunnel. Other routes of infection such as transcolonic, hematogenous or through the female genital tract are uncommon, while peritonitis precipitated by occult contamination of the dialysis fluid is thought to be rare [1].

Outbreaks of peritonitis among intermittent peritoneal dialysis (IPD) patients were previously linked to the use of contaminated water baths for warming the dialysate $[2,3]$. In those cases, it appears likely that the dialysate became contaminated when the prong of the fluid administration set was inserted through the rubber bung on the dialysate bottles.

Cheng et al [4] attributed a poly-microbial outbreak of peritonitis among patients undergoing intermittent peritoneal dialysis (IPD) treatment to environmental contamination by air-borne organisms secondary to hospital renovation. Patients undergoing inpatient CAPD treatment were not affected by that outbreak. They postulated that organisms with high air counts may drop into the connecting system during the exchange procedure, 
Figure 1: Fungal mass in a new unused bag

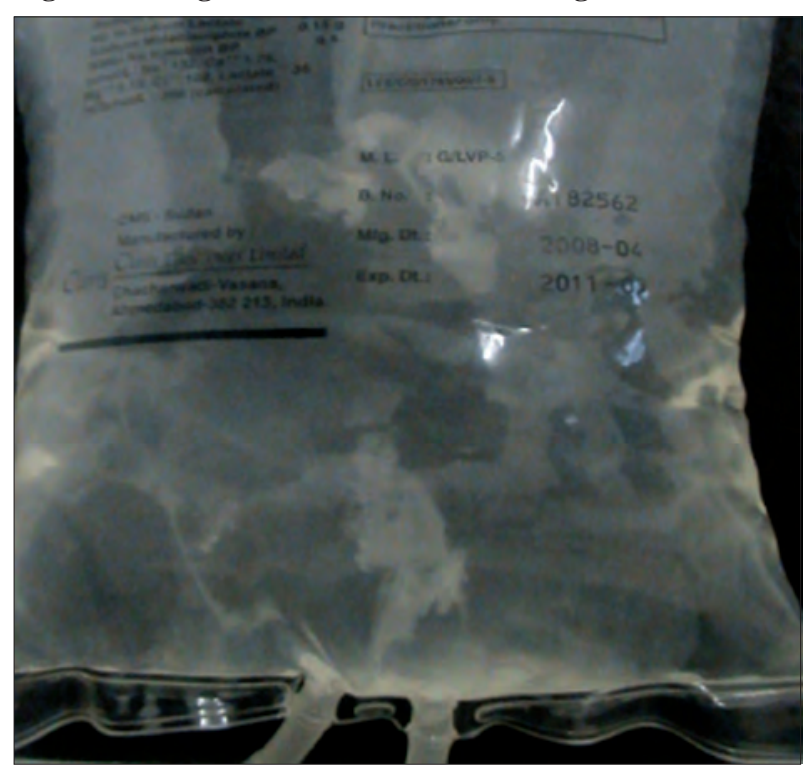

and that the flush-before-fill technique employed by CAPD patients effectively prevents the subsequent entry of these organisms into the peritoneal cavity. IPD patients start treatment with an empty abdomen and are deprived from the protection of the flush-before-fill technique. Greaves et al also reported an outbreak of fungal peritonitis due to Candida parapsilosis among IPD patients. They attributed the outbreak to colonization of various areas of the PD Unit with the organism which had been also isolated from pigeon guano obtained from window-sills. The number of cases of peritonitis due to this organism decreased markedly after bird-proof netting was installed [5].

In this report, we describe an outbreak of CAPD related peritonitis that followed the use of potentially contaminated PD fluid.

\section{Outbreak description}

CAPD was introduced in the adult nephrology unit at Soba University Hospital, Khartoum, Sudan, in December 2008. PD fluids were supplied by one supplier (Claris $^{\mathrm{TM}}$; Claris Life Sciences Limited) utilizing the twin-bag disconnect-system. In this brand the twin-bags are pre-attached to the Y-set, spiking is not required and the only connection the patient needs to make is between the transfer set and the extension tubing. All patients used the flush-before-fill technique. Patients' outcomes were satisfactory during the first six months, with two episodes of bacterial peritonitis in 43 patient months and an average $\mathrm{Kt} / \mathrm{V}$ of 2.2 .
Figure 2: fungal mass in the effluent of one of the patients

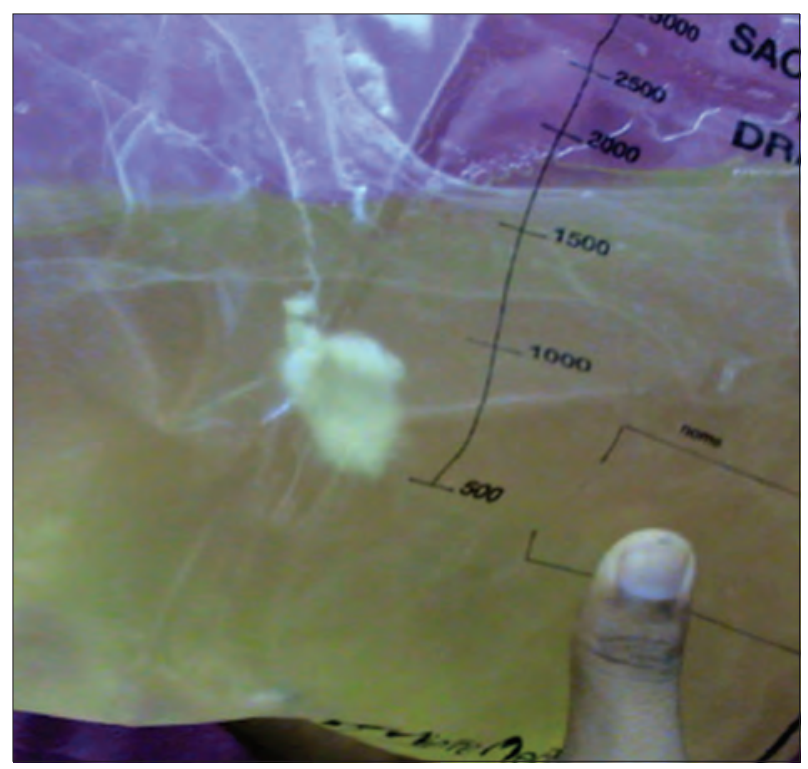

In June 2009, a new supply of PD fluids was delivered to the hospital store from the same supplier and came into use. Four days later, a PD nurse noted a whitish membrane-like material floating inside a new unused dialysis bag containing $2.5 \%$ dextrose that remained from the original stock. This proved on culture to be fungal contamination with Penicillium spp. (Figure 1).

Three days following this incident, a patient presented complaining of high grade fever, abdominal pain and turbid effluent. Inspection of the effluent revealed marked turbidity and floating mould (figure 2). At this point, the possibility of wide spread contamination of the PD fluid stock was considered likely. All the 15 patients maintained on CAPD in the unit were called and shifted to another brand of PD fluids (Clear-Flex ${ }^{\mathrm{TM}}$; Baxter Health Care).

During the following week, another five cases of peritonitis were diagnosed. One patient presented two days later in a very ill condition with turbid effluent. The remaining four patients were largely asymptomatic and were diagnosed based on elevated effluent WBCs on screening (Table 1).

Overall, six patients were affected by this outbreak; five males and one female. Their mean age was $43 \pm 21$ years (range $17-65$ years), and their mean duration on PD was 4.8 months \pm 1.6 (range: $3.3-7$ months). This was the first peritonitis episode for all patients, and none of them received systemic antibiotics during the preceding month. No patient reported a break in the aseptic technique during the previous days. One patient noticed that one of 
Table 1: Clinical characteristics, management and outcome of the six patients diagnosed to have PD related peritonitis during the outbreak

\begin{tabular}{|c|c|c|c|c|c|c|}
\hline & $\begin{array}{l}\text { Initial } \\
\text { presentation }\end{array}$ & $\begin{array}{l}\text { Effluent } \\
\text { appearance* } \\
\text { and microscopy }\end{array}$ & WBCs & Culture & Treatment & Outcome \\
\hline 1 & $\begin{array}{l}\text { fever } \\
\text { abdominal pain } \\
\text { vomiting } \\
\text { hypotension }\end{array}$ & $\begin{array}{l}\text { turbid / fungal } \\
\text { hyphae seen in } \\
\text { effluent by direct } \\
\text { microscopy }^{\dagger}\end{array}$ & 2115 & $\begin{array}{l}\text { Coliform } \\
\text { bacilli }\end{array}$ & $\begin{array}{l}\text { ketoconazole } \\
\text { amphotericin B } \\
\text { antibiotics }\end{array}$ & $\begin{array}{l}\text { moderate improvement on medical treatment } \\
\text { catheter removed } 16 \text { days later } \\
\text { symptoms resolved after catheter removal } \\
\text { shifted permanently to HD }\end{array}$ \\
\hline 2 & $\begin{array}{l}\text { fever } \\
\text { abdominal pain } \\
\text { vomiting } \\
\text { hypotension }\end{array}$ & turbid & 2000 & $\begin{array}{l}\text { Coagulase } \\
\text { negative } \\
\text { Staphylococci }\end{array}$ & $\begin{array}{l}\text { ketoconazole } \\
\text { amphotericin B } \\
\text { antibiotics }\end{array}$ & $\begin{array}{l}\text { prompt clinical improvement within } 3 \text { days } \\
\text { catheter replaced after } 14 \text { days } \\
\text { still maintained on CAPD six months later }\end{array}$ \\
\hline 3 & $\begin{array}{l}\text { vomiting } \\
\text { hypotension }\end{array}$ & turbid & 1420 & no growth & $\begin{array}{l}\text { ketoconazole } \\
\text { amphotericin B }\end{array}$ & $\begin{array}{l}\text { prompt clinical improvement within } 3 \text { days } \\
\text { catheter replaced after } 20 \text { days } \\
\text { still maintained on CAPD six months later }\end{array}$ \\
\hline 4 & abdominal pain & turbid & 1100 & no growth & $\begin{array}{l}\text { ketoconazole } \\
\text { amphotericin B }\end{array}$ & $\begin{array}{l}\text { prompt clinical improvement within } 3 \text { days } \\
\text { catheter replaced after } 11 \text { days } \\
\text { still maintained on CAPD six months later }\end{array}$ \\
\hline 5 & no symptoms & clear & 160 & no growth & ketoconazole & $\begin{array}{l}\text { effluent WBCs promptly returned to normal } \\
\text { catheter was not removed } \\
\text { still maintained on CAPD six months later }\end{array}$ \\
\hline 6 & no symptoms & clear & $242^{\ddagger}$ & no growth & ketoconazole & $\begin{array}{l}\text { effluent WBCs promptly returned to normal } \\
\text { catheter was not removed } \\
\text { still maintained on CAPD six months later }\end{array}$ \\
\hline
\end{tabular}

\footnotetext{
* The effluent of all these patients contained a whitish, thin, web-like material that later condensed into a fluffy white mass

$\dagger$ This is the only patient in whom fungal hyphae were identified in the effluent by direct microscopy

$\ddagger$ Patient no. 6 was being treated for tuberculous peritonitis but his previous effluent WBCs were within normal range
}

the PD solution bags was leaking while preparing it for connection, but discarded the bag before use.

Another patient had a single cuffed Tenckhoff catheter inserted during a protracted episode of acute renal failure. His kidney function gradually improved and he remained off dialysis for approximately two months while his PD catheter was in place. He was exposed to a single bag from the second supply. When we removed his catheter, its lumen was filled, albeit not obstructed, with a yellowish substance that appeared to extend from the lumen into the catheter pores. Direct microscopy only revealed aggregates of pus cells in a hyalinaceous material and no organism was isolated on culture (figure 3).

Enquiry revealed that this supply of PD fluid was stored for a considerable duration in a warm and humid environment during transportation. A survey of the unit's stock was arranged. We inspected against a bright light 1469 bags of PD fluids including 605 bags that contained $1.5 \%$ dextrose and 864 bags that contained $2.5 \%$ dextrose. Overall, 56 bags (3.8\%) displayed some sign of damage;
43 bags merely lost the negative vacuum between the inner bag and the outer plastic envelope, eight bags had a torn outer envelope, one bag had a detached tubing, one bag displayed discoloration of the plastic inner bag, and three bags $(0.2 \%)$ contained mold within the dialysis fluid. The three bags which contained fungus all contained $2.5 \%$ dextrose. All of them had lost the negative vacuum between the inner bag and the outer plastic envelope, but had no obvious tears in the envelope and no obvious fluid leakage. They were found in three different card boxes and were from two different batches, manufactured 14-15 months before, and within their validity date. Culture of all bags also revealed Penicillium spp.

During the latter half of the year, we recorded six episodes of bacterial peritonitis over 106.9 patient months. The peritonitis rate before the outbreak was one episode in 21.7 patient-months. This sharply rose to one episode in 2.5 patient-months during the month of the outbreak, and dropped down to one episode in 17.8 patient-months in the 6-months following the outbreak (Figure 4). 
Figure 3: probable fungal mass in the lumen of a removed Tenckhoff catheter

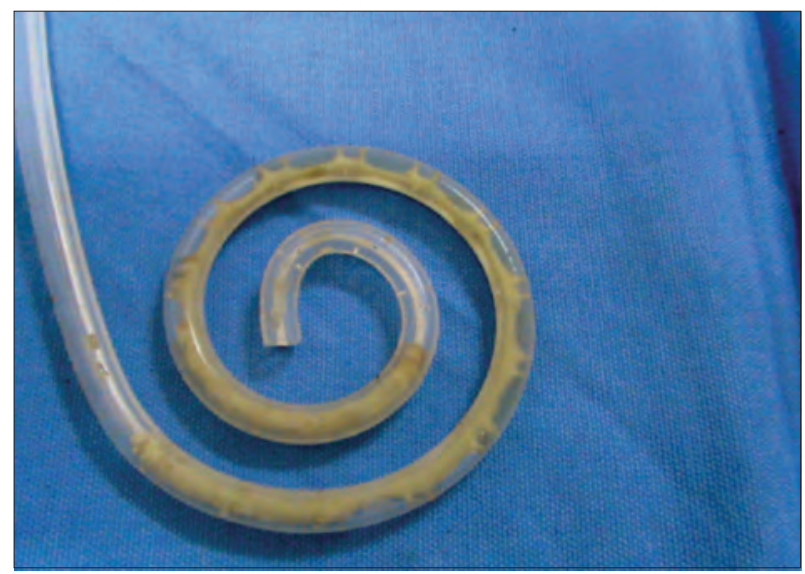

\section{Discussion}

The high glucose concentration of the dialysate (1.5-4.5\%) renders it an optimal culture medium for fungi. Fungal contamination of dialysis solutions may occur through pin holes and/or small cracks formed during transportation and storage. Visible fungal growth within unused dialysis bags has been reported soon after commercially prepared plastic dialysate bags became available for the management of IPD patients. In 1967, Stewart et al reported finding seven PD bags over an 18 months period that had small leaks at the neck and an obvious mass of fungus growing in the fluid of the inner bag. Further inspection of the hospital stock detected 18 containers ( $2 \%$ of the stock) from different batches that had obvious leakage, including 12 containers that had a mycelial mass within the inner bag [6]. Marzec et al also reported three isolates of Paecilomyces variotii from unused dialysate bags. In each occasion, macroscopic fungal elements were noted by a patient as he prepared the dialysate for use. One of the patients subsequently developed peritonitis caused by $P$. variotii [7].

Another report of dialysate bag contamination by fungi was dated in 1999. Following detection of a fungal mass within an unused dialysate bag, the hospital stock was surveyed, and culture was performed from 49 randomly selected bags ( $10 \%$ of the stock). Fungi were isolated from two bags (4\%) [8].

The bags of the dialysate are encased in an external plastic envelope. During sterilization, a vacuum is created between the bag and its external envelope. The persistence of this vacuum and the absence of fluid in the interspaces are reliable indicators of an intact package and preserved sterility of the solution [1]. The validity of this statement is supported by our findings in this survey. All four bags that contained visible mould had lost the vacuum between the bag and its external envelope, while no mould could be seen within bags that maintained this vacuum. Although no visible fluid leak could be detected, contaminants are likely to have gained access through microscopic punctures in the bag. It appears prudent

Figure 4: Peritonitis rates (shown as patient-months per episode) in our unit in the six months that preceded the outbreak (phase 1), during the outbreak (phase 2), and in the six months that followed the outbreak (phase 3); phase 2 duration was one month, starting on the day of first using the contaminated PD fluids and ending 3 weeks after all patients were shifted to another supplier

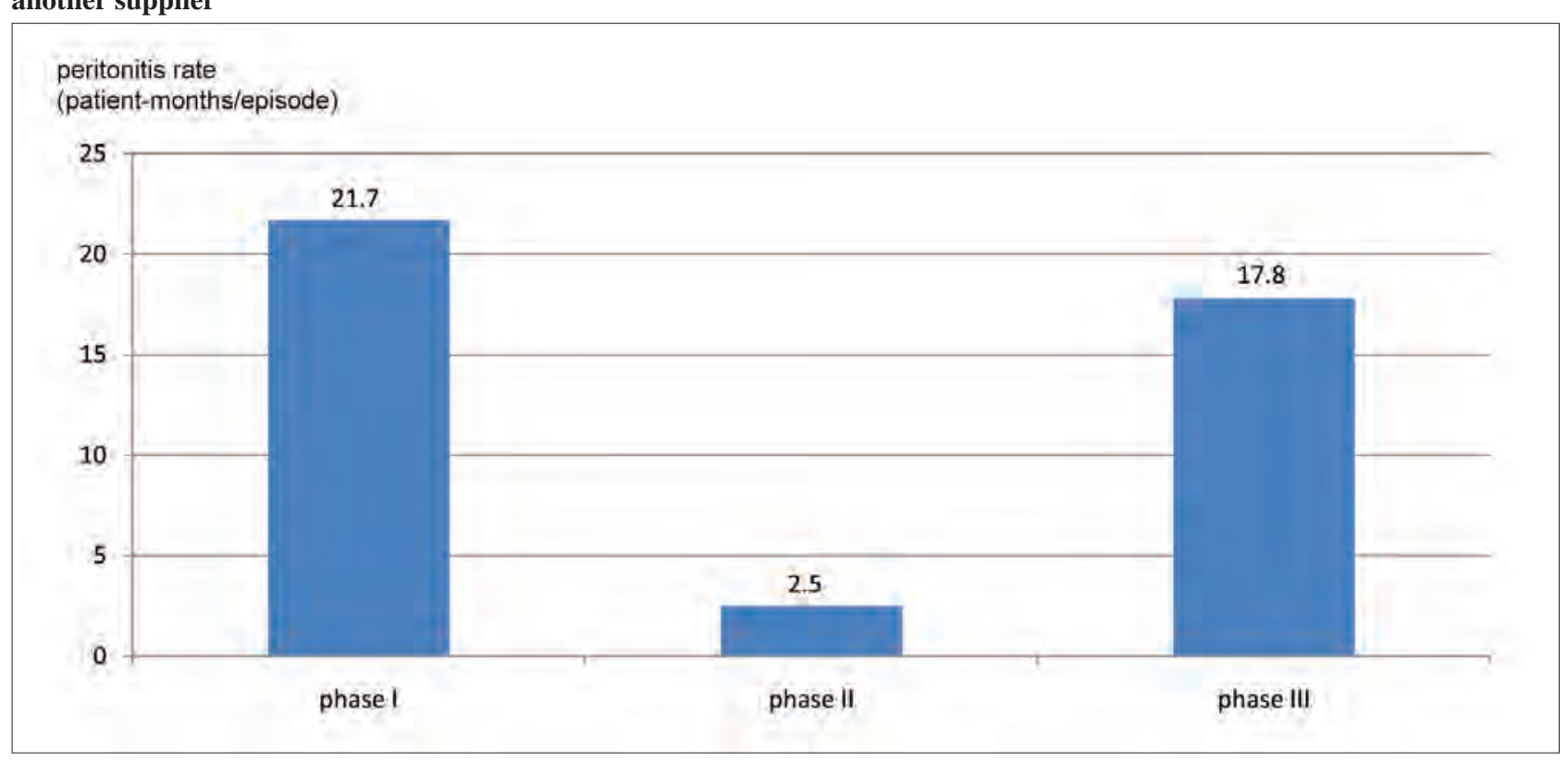


that every patient should be educated to inspect dialysis bags for the presence of this vacuum before use. Patient should be directed to discard any bag that has lost this guarantee of sterility rather than risk the possibility of using a potentially breached bag.

Fungi were not isolated by culture from any of the patient, and deformed fungal hyphae were detected by direct microscopy in only one patient. Bacterial pathogens were isolated from two patients, including the only patient in whom effluent fungal hyphae were identified. These two patients were the only patients who were symptomatic at presentation, and received empiric treatment with broad spectrum antibiotics and antifungal agents. Antibiotics were later modified according to culture results and antifungal treatment continued despite failure to isolate fungi from the effluent. The remaining four patients were asymptomatic upon diagnosis, although two of them later developed abdominal pain, vomiting and hypotension. Those four patients had negative culture results and were not prescribed antibiotics; all of them responded to treatment with systemic antifungal agents.

The International Society of Peritoneal Dialysis (ISPD) guidelines recommend immediate removal of the PD catheter upon diagnosis of fungal peritonitis [9]. Lack of fungal growth on dialysate culture and the prompt response to treatment made us rather hesitant to remove the patient's catheters. In our case, all patients were from remote areas, and even a transient shift to hemodialysis would have been quite cumbersome.

Theoretically, removal of the catheter in fungal peritonitis could stop continuous seeding of organisms embedded in it. On the other hand, continuation of PD could allow continuous drainage of inflammatory debris that might otherwise predispose to peritoneal adhesion and abscess formation. Wong et al managed 13 episodes of Candida peritonitis with systemic antifungal agents and deferred catheter replacement. The dialysate effluent cleared in 11 patients $(84.6 \%)$ after $13.2 \pm 3.3$ days of treatment, and the study group had significantly lower technique failure rate $(30.8 \%$ versus $78.6 \%)$ similar mortality (30.7\% versus $28.5 \%$ ) and length of hospitalization (48.5 \pm 30.2 versus $57.0 \pm 37.7$ days) than historical controls [10]. This study is limited by its retrospective nature and differences in antifungal agents used in the two groups. It also contradicts many other reports that emphasize the negative impact on prognosis of delaying catheter removal in fungal peritonitis [11].

Expectant management proved unwise in the case of one patient whose effluent, unlike the others, failed to clear rapidly. Persistence in peritoneal lavage for 16 days in the hope of clearing the effluent from visible mould proved unfruitful. If this approach of deferring catheter removal is adopted, the delay should probably not exceed five days unless prompt clearance of the effluent is achieved.

Fungi are the most likely culprit in contaminated dialysis fluids, and solutions with higher dextrose concentrations are more susceptible [6]. In previous reports of contaminated dialysate bags, isolation of a single contaminant was rather common. In the 1967 report, one organism was isolated in almost half the cases. Penicillium was the commonest culprit, either alone or in combination. Yeasts were the second most common isolate, while Cladosporium, Cephalosporium, Paecilomyces and bacteria were only occasionally detected [6]. In a report by Febré et al, Chaetomium globosum and Chrysonilia sithopila were isolated from two different samples, and bacteria were not detected [8].

Particular care in the transportation and storage of PD fluids is necessary. This is particularly important in large countries where PD supplies are likely to be repeatedly transported and stored in different locations before they reach the patient's home.

\section{Conclusion}

Contamination of PD fluids can occur and may result in infections. Particular care is necessary in handling and storing the fragile plastic bags of dialysate. Patients should be instructed on the meticulous examination of each dialysis bag before usage. Any bag that has lost the vacuum between the inner bag and its outer envelope is potentially breached and should not be used.

\section{References}

1. Maher JF, editor. Replacement of renal function by dialysis: a text book of dialysis. 3rd ed. Netherlands: Kluwer Academic Publisher Group; 1989. p 547.

2. Yuen KY, Seto WH, Ching TY, Cheung WC, Kwok Y, Chu YB. An outbreak of Candida tropicalis peritonitis in patients on intermittent peritoneal dialysis. J Hosp Infect. 1992 Sep;22(1):65-72.

3. Abrutyn E, Goodhart GL, Roos K, Anderson R, Buxton A. Acinetobacter calcoaceticus outbreak associated with peritoneal dialysis. Am J Epidemiol. 1978 Apr;107(4):328-35.

4. Cheng VC, Lo WK, Woo PC, Chan SB, Cheng SW, Ho M, Yuen KY. Polymicrobial outbreak of intermittent peritoneal dialysis peritonitis during external wall renovation at a dialysis center. Perit Dial Int. 2001 MayJun;21(3):296-301.

5. Greaves I, Kane K, Richards NT, Elliott TS, Adu D, Michael J. Pigeons and peritonitis? Nephrol Dial Transplant. 1992;7(9):967-9. 
6. Stewart WK, Anderson DC, Wilson MI. Hazard of peritoneal dialysis: contaminated fluid. Br Med J. 1967 Mar;1(5540):606-7.

7. Marzec A, Heron LG, Pritchard RC, Butcher RH, Powell HR, Disney AP, Tosolini FA. Paecilomyces variotii in Peritoneal Dialysate. J Clin Microbiol. 1993 Sep;31(9):2392-5.

8. Febré N, Silva V, Medeiros EA, Godoy P, Reyes E, Halker E, Fischman O. Contamination of peritoneal dialysis fluid by filamentous fungi. Rev Iberoam Micol. 1999 Dec;16(4):238-9.

9. Piraino B, Bailie GR, Bernardini J, Boeschoten E, Gupta A, Holmes C, Kuijper EJ, Li PK, Lye W, Mujais S,
Paterson DL, Fontan MP, Ramos A, Schaefer F and Uttley L. Peritoneal dialysis-related infection recommendation: 2005 update. Perit Dial Int. 2005;25:107-31.

10. Wong PN, Lo KY, Tong GMW, Chan SF, Lo MW, Mak SK, Wong AKM. Treatment of fungal peritonitis with a combination of intravenous amphotericin B and oral flucytosine, and delayed catheter replacement in continuous ambulatory peritoneal dialysis. Perit Dial Int 2008;28(2):155-62.

11. Lye WC. Catheter removal for fungal peritonitis: sooner or later? Perit Dial Int. 2008 Mar-Apr;28(2):130-3. 